\title{
General considerations and updates in pediatric gastrointestinal diagnostic endoscopy
}

Yong Joo Kim, M.D.

Department of Pediatrics, School of Medicine, Hanyang University, Seoul, Korea

Received: 23 July 2010, Accepted: 23 August 2010 Corresponding author: Yong Joo Kim, M.D.

Department of Pediatrics, Hanyang University Hospital, 17 Haengdang-dong, Sungdong-gu, Seoul 133-792, Korea

Tel: +82.2-2290-8390, Fax: +82.2-2297-2380

E-mail: kyjoo@hanyang.ac.kr

Copyright (C) 2010 by The Korean Pediatric Society
Gastrointestinal and colonic endoscopic examinations have been performed in pediatric patients in Korea for 3 decades. Endoscopic procedures are complex and may be unsafe if special concerns are not considered. Many things have to be kept in mind before, during, and after the procedure. Gastrointestinal endoscopy is one of the most frequently performed procedure in children nowadays, Since the dimension size of the endoscopy was modified for pediatric patients 15 years ago, endoscopic procedures are almost performed routinely in pediatric gastrointestinal patients. The smaller size of the scope let the physicians approach the diagnostic and therapeutic endoscopic procedures. But this is an invasive procedure, so the procedure itself may provoke an emergence state. The procedurerelated complications can more easily occur in pediatric patients. Sedation-related or procedure-related respiratory, cardiovascular complications are mostly important and critical in the care. The endoscopists are required to consider diverse aspects of the procedure - patient preparation, indications and contraindications, infection controls, sedation methods, sedative medicines and the side effects of each medicine, monitoring during and after the procedure, and complications related with the procedure and medicines - to perform the procedure successfully and safely. This article presents some important guidelines and recommendations for gastrointestinal endoscopy through literature review.

Key words: Pediatric, Gastrointestinal endoscopy, Child

This is an open-access article distributed under the terms of the Creative Commons Attribution Non-Commercial License (http://creativecommons.org/licenses/by $\mathrm{nc} / 3.0 /$ ) which permits unrestricted non-commercial use, distribution, and reproduction in any medium, provided the original work is properly cited.

\section{Introduction}

The gastrointestinal endoscopies in pediatric patients are commonly performed in the tertiary referral medical institutes in Korea. Observation for the guidelines is very important as much as the skill of the physicians. Guidelines for trainees to ensure competence have been issued by the North American Society of Pediatric Gastroenterology and Nutrition in $1999^{1)}$. The endoscopists are required to follow the recommendations of the endoscopic procedures. The physicians need to understand patient preparation, indications and contraindications, infection controls, sedation methods, sedative medicines and the side effects 
of each medicine, monitoring during and after the procedure, and complications.

\section{Patient and parent preparations}

Understanding of the methods and preparations for gastrointestinal endoscopy (GIE) on the part of pediatric patients and their families allows the procedure to be performed without difficulties and with good outcome. It is recommended that the preparation should start early, and sufficient information should be provided to the patients and their families. The endoscopist should decide on the sedation methods to be used on the basis of the patient's past experiences with the procedure. Parents and children often express anxiety about separation during the procedure; thus, parental presence is warranted during the preprocedure educational period. Parental presence during the induction of anesthesia has been approved to alleviate stress in both children and parents ${ }^{2}$. Loss of inhibition and agitation in patients are common during the induction phase. Informed parents may help reduce fears and worries in their child. Child life specialists may also participate, and they can assist the child and the family to cope with the psychological aspects of the procedures ${ }^{3}$. Psychological preparations significantly reduce anxieties in the patient and the family ${ }^{4}$. Such specialist care are available in developed countries.

\section{Preprocedure assessments}

To determine the patients' physical and emotional readiness for the procedure, developmental, physical, cognitive, and laboratory assessments are done. The assessment includes systemic review and physical examination. Body weight and baseline vital signs, including blood pressure, pulse, temperature, respiratory and heart rates, oxygen saturation, level of consciousness, and pain scale score, are obtained in this phase. Recent and current medications are checked by the admitting nurse or doctors. Use of homeopathic, herbal, and dietary supplements is also determined because these substances may interact with sedation medications.

The respiratory system should be examined thorough airway assessment. Examination of loose teeth, oral piercings, and enlarged tonsils is important. Loose teeth may be accidentally dislodged and enter the patient's airway as a foreign body. Oral and tongue piercings must be removed for the same reason. Patients with enlarged tonsils may experience obstructive apnea and should be evaluated by the physician before sedation or anesthetization.

Laboratory examinations, including coagulation and liver function tests, are also important. The endoscopic procedure is contraindicated in most cases of coagulopathy. The doses of sedative medications should be lowered and the patient should be carefully monitored in the event of poor liver function.

\section{Informed consent}

Obtaining informed consent is an important initial step, as well as providing the patient and family with sufficient information about the potential risks and benefits of the procedure. Doctors explain the risks of sedation and the steps in the procedure. The important elements of this discussion should then be acknowledged in writing. Writing and signing of the informed consent form enforces a sense of trust between the patient and the physician, and provides legal documentation. Informed consent forms for pediatric patients can be obtained from the Internet home page of the Korean Society of Gastrointestinal Endoscopy (www.gie.or.kr).

\section{Contraindications}

Absolute contraindications for upper endoscopy include cardiovascular collapse, unstable airway, deteriorating pulmonary or neurologic status, intestinal perforation, peritonitis, and cervical traumas. The procedure should be delayed or cancelled in the absence of signed consent or competent medical personnel. Relative contraindications are recent digestive surgery, bowel obstruction, coagulopathy, severe thrombocytopenia, prematurity, and recent food intake. Hypoglycemic episodes should be a concern for patients with insulin-dependent diabetes. These patients should be prioritized in the endoscopy list and advised to reduce the amount of morning insulin therapy. In a child with hematemesis, an abdominal radiograph must be obtained to determine the presence of any intestinal obstruction or perforation ${ }^{5)}$.

\section{Dietary restrictions}

To reduce the potential for aspiration of gastric contents during sedation, preendoscopy dietary restrictions are required. Patients with large residual gastric fluid volumes with a low $\mathrm{pH}$ are at increased risk for aspiration injury ${ }^{6}$. Traditionally, fasting for solids for 6 hours and liquids for 2-4 hours is recommended. A longer fasting time may be required for conditions such as achalasia and gastric outlet obstruction because retained food in the esophagus or stomach can increase the risk of aspiration ${ }^{7}$.

Dietary restrictions are designed to minimize the volume of gastric acid at the time of sedation. Conventional recommendations for a prolonged fast before sedation have been challenged by 2 
studies demonstrating the adequacy of a brief fast. Ingebo et al. ${ }^{8)}$ found that the fasting time poorly correlates with the volume of gastric fluid at the time of endoscopy and that clear fluids empty rapidly from the stomach in children. Schriener et al. ${ }^{9)}$ found no difference in gastric volume or $\mathrm{pH}$ in children allowed clear liquids 2-3 hours before induction of anesthesia compared with conventional prolonged fasting.

The following presedation dietary guidelines were adapted from the American Society of Anesthesiologists (ASA) ${ }^{10)}$. Children should be offered clear liquids (this includes breast milk but not other milk or formula) up to 2-3 hours before sedation to avoid dehydration. Infants less than 6 months may receive formula up to 4-6 hours and clear liquids up to 2 hours before sedation. For patients older than 6 months, solids and nonclear liquids should be held for 6-8 hours before sedation. However, longer periods of fasting may be required for conditions such as achalasia and gastric outlet obstruction, because retained food in the upper gastrointestinal lumen may increase the risk of aspiration.

According to the guidelines of the Korean Society of Gastrointestinal Endoscopy ${ }^{11)}$, the recommended fasting time is 4 hours in infants younger than 5 months old, 6 hours in infants 6-36 months old, and more than 8 hours in children older than 36 months old.

\section{Sedation and patient monitoring}

Nonsedated endoscopic procedures have been documented and assessed to be safe in motivated pediatric patients ${ }^{12)}$. However, $80 \%$ of these patients would choose to be sedated if upper endoscopy should be repeated. The goals of sedation are maximal comfort, cooperation, amnesia, and loss of anxiety ${ }^{13}$. Children may require no sedation (diagnostic sigmoidoscopy in infants), intravenous sedation, or general anesthesia ${ }^{14)}$.

The so-called lytic or Toronto cocktail ${ }^{15)}$ (the combination of intramuscular meperidine, promethazine, and chlorpromazine) has been used for many pediatric procedures. Nevertheless, the efficacy of its sedative effect is limited in GIE, and an intravenous sedation must be favored.

Intravenous anesthetics are popularly used either with an endotracheal tube or with a natural airway. A short-acting agent such as propofol provides the advantage of a low incidence of airway obstruction and postoperative nausea and vomiting, as well as rapid recovery from general anesthesia with a low incidence of emergence delirium. The bolus dose of propofol is $1-3.5 \mathrm{mg} / \mathrm{kg}$ of body weight, followed by a titrated infusion of $0.1-0.3 \mathrm{mg} / \mathrm{kg}$ body weight/ minute. Powers et al. ${ }^{16)}$ reported the prospective study results of the sedative effects of propofol in painful pediatric procedures. The patients required a mean bolus dose of $2.23 \mathrm{mg} / \mathrm{kg}$ and a mean titrating dose of $0.52 \mathrm{mg} / \mathrm{kg} /$ minute to achieve good sedation. The mean time until awakening was 14.9 minutes.

Alternatively, a combination of ketamine, midazolam, and short-acting opioids also has the advantage of a low incidence of airway obstruction, although laryngospasm and delirium occur occasionally. Nasal oxygen supplementation is recommended ${ }^{177}$.

Other drugs have been proposed, e.g., intramuscular ketamine, especially in children older than 7 years ${ }^{18)}$. Chloral hydrate and atropine are frequently used in addition to a standard regimen of sedation.

Midazolam combined with fentanyl produces rapid-onset anxiolysis, hypnosis, amnesia, and analgesia, with a relatively brief duration of action in children as well as in adults. This combination has a comfortable margin of safety against complete loss of consciousness. Following an initial dose, both midazolam and fentanyl are titrated using incremental doses every 3-5 minutes until an adequate level of sedation is achieved.

The safety of fentanyl and midazolam intravenous sedation was reported in a prospective study of 1,578 procedures (758 upper endoscopies, 116 colonoscopies, and 352 combined procedures $)^{19)}$. This study noted serious adverse events (apnea) in only 2 children. Mild or moderate adverse events included oxygen desaturation $<92 \%$ for less than 20 seconds in 100 (9\%), vomiting in 64 (5\%), agitation in $15(1 \%)$, oxygen desaturation $<92 \%$ greater than 20 seconds in $12(0.7 \%)$, and rash in $8(0.7 \%)$. No cardiopulmonary resuscitation or sedation reversal was required, and no patient required hospitalization. The authors concluded that intravenous sedation with fentanyl and midazolam is safe and that serious adverse events are rare.

Another prospective study on the safety of propofol use in gastrointestinal endoscopy was reported ${ }^{20)}$. Propofol was used as a sedative in 811 pediatric patients. Sedation was achieved in all procedures, and all but $3(0.4 \%)$ were successful. None of the patients required intubation. Stridor with signs of upper airway obstruction occurred in $1.7 \%$. Laryngoscopy was required to manage difficulties in introducing the gastroscope in 2.0\%. Major desaturation requiring a short course of ventilation occurred in $0.7 \%$, and transient desaturation that resolved spontaneously occurred in $12 \%$. Administration of propofol by nonanesthesiologists for gastroscopic examinations in children was successful, but there was a small risk of potentially severe complications.

A recent study reported that the combination use of propofol and midazolam in pediatric GIE was safe and effective as in adult patients ${ }^{21}$.

The method of sedation for endoscopy in children is really 
selective. Many factors must be considered, including the patient's condition, ASA classification, the type of procedure (i.e., diagnostic versus therapeutic), the anticipated level of patient's cooperation, the parents' and patient's preferences, as well as the endoscopist's experience $^{22}$. There is consensus that general anesthesia is necessary for complicated therapeutic procedures, patients with neurologic problems, patients at high risk for cardiopulmonary complications, and uncooperative patients who have failed intravenous sedation ${ }^{23)}$.

The widespread use of sedation in GIE in children imposes the need for resuscitation and monitoring equipment in the endoscopy room. Standard monitoring must include an electrocardiogram, a blood pressure monitor, and a pulse oximeter. To minimize the adverse reactions, it is recommended to titrate the sedative drugs until the patients are sufficiently sedated. A minimum of 2 assistants are required. One assistant supports the airway, assesses vital signs, and administers medications, while the other assists in biopsies or other endoscopic interventions. A third assistant may be occasionally needed to restrain an agitated child.

The endoscopy room must be equipped with pressurized $100 \%$ oxygen and additional suction outlets. Resuscitation equipment, including an anesthesia bag with large and small masks, medications, and equipment for airway intubation, and a defibrillator must be immediately available.

\section{Postprocedure monitoring}

Monitoring settings during the procedure are continued, especially for small infants for the next 15-30 minutes, in the recovery room or on the ward. If the patient is sleeping, the patient is placed in the lateral position. If midazolam was used, the child should stay in the ward for a minimum of 2 hours. Amnesia can persist up to 8 hours. Drinks are allowed 1 hour after the end of the endoscopy; special attention is required to avoid choking if topical anesthetic spray was used. The American Academy of Pediatrics has provided discharge criteria as follows ${ }^{24)}$. Cardiovascular function and airway patency are satisfactory and stable. The patient is easily arousable, and protective reflexes are intact. The patient can talk (if age appropriate). For a very young or handicapped child, incapable of the usual expected responses, the presedation level of responsiveness or a level as close as possible to the normal level for that child should be achieved. The state of hydration is adequate.

\section{Antibiotic prophylaxis}

Bacteremia is common following some forms of therapeutic endoscopic procedures, such as dilatation, injection sclerotherapy, or percutaneous endoscopic gastrostomy (PEG), and can occur with diagnostic endoscopy alone. Fortunately, complications resulting from dissemination of endogenous bacteria are uncommon, and infective endocarditis is an extremely rare complication. Furthermore, for most diagnostic and therapeutic procedures, there is scant evidence that antibiotic prophylaxis can reduce the incidence of infective complications.

According to the guidelines of the American Heart Association (AHA) and the American Society of Gastroenterological Endoscopy (ASGE) ${ }^{25,26)}$, administration of prophylactic antibiotics is recommended only in select situations. Specific clinical conditions recognized as such are cardiac lesions with high or moderate risk of bacterial endocarditis. Durack ${ }^{27)}$ has established a list of high-, moderate-, and low-risk patients. Prophylactic antibiotics are recommended for high-risk patients (i.e., with prosthetic valve, surgical pulmonary shunt, previous endocarditis, or complex congenital heart disease). In addition to heart diseases, the following are candidates for prophylactic antibiotic therapy: patients with neutropenia; patients with central lines, prosthetic devices, ventriculoperitoneal shunt, and ascites ${ }^{28}$; and patients on interventional procedures (stricture dilatation, sclerotherapy, $\mathrm{PEG}^{29)}$ ). Antibiotic recommendations are not standardized, with the ASGE proposing prophylaxis only in high-risk patients. On the other hand, the AHA has recently proposed a simplified regimen for moderate-risk patients.

Gram-positive bacteria are the most commonly implicated organisms. In case of cardiac risk, the recommended regimen is as follows ${ }^{30,31)}$ : a combination of ampicillin and gentamicin intravenously or intramuscularly 30 minutes before the procedure. Additional oral amoxicillin 6 hours later or intravenous ampicillin can be used. In patients allergic to penicillin, vancomycin or teicoplanin can replace amoxicillin.

The Endoscopy Committee of the British Society of Gastroenterology recently reported guidelines on prophylactic antibiotic preventions. The guideline states that antibiotic prophylaxis is no longer recommended for the prevention of infective endocarditis in patients with cardiac risk factors who undergo diagnostic or therapeutic endoscopy (Evidence Grade III, Recommendation Grade B). The use of antibiotics is recommended for selected patients with evidence of infections ${ }^{32)}$.

\section{Complications}

Simple diagnostic endoscopy, including mucosal biopsy, confers very few serious complications. The risks of therapeutic endoscopy depend on particular interventions. If performed by a well-trained 
pediatric endoscopist, complication occurs in less than $1 \%{ }^{33)}$. It is important for the endoscopist to anticipate the possibility of complication and be prepared for appropriate management.

During the procedure, desaturation below $90 \%$ occurs in about $10 \%$ of children ${ }^{34}$. Nasal oxygen application is sufficient to correct this desaturation. Most complications in children have been related to percutaneous gastrostomy, esophageal dilation, variceal sclerotherapy, and foreign body removal.

Major complications are bowel perforation and hemorrhage. Minor complications are nausea, transient hypoxemia, and transient odynophagia. To minimize the risk, it is very important to never proceed scope if the endoscopic view is not clear. Fleischer et al. ${ }^{35)}$ reported prospective data collected over 1 year, including 3,287 procedures. The overall complication rate was $1.9 \%, 2$ deaths $(0.06 \%)$ and 3 bowel perforations $(0.09 \%)$. Six patients required surgical intervention $(0.18 \%)$, and 16 patients had cardiopulmonary problems $(0.49 \%)$. Duodenal hematoma has been reported in children following routine diagnostic endoscopic biopsies. This complication is rare, but seems to occur more often in children ${ }^{36}$.

Infections can occur due to the patient's own microbial flora and those from other patients through a contaminated endoscope. The most frequent microorganisms are Salmonella species, Pseudomanas aeruginosa, Mycobacterium species, and Helicobacter pylori ${ }^{377}$. These infectious complications can be seen in cardiac-risk groups. Bacteremia is rare in patients with no risk; thus, prophylactic antibiotics are required only for selected patients.

\section{Advances in pediatric endoscopy}

\section{Wireless capsule endloscopy (WCE)}

The use of WCE in children was approved by the FDA in 2003. More than 500,000 patients, including children, have been safely evaluated by this unique modality. PillCam ${ }^{\circledR}$ SB video capsule is vitamin sized, measures $11-26 \mathrm{~mm}$, and weighs less than $4 \mathrm{~g}$. It provides resolution down to $0.1 \mathrm{~mm}$; an upper GI typically identifies lesions $0.5 \mathrm{~mm}$ or larger.

The general indication for WCE is evaluation of suspected small bowel diseases-abdominal pain, celiac disease, inflammatory bowel diseases, and obscure GI bleeding. This tool can be used to monitor the treatment status of small bowel diseases such as small bowel lesion in Henoch-Schöenlein purpura ${ }^{38)}$ or graft-versus-host diseases $^{33)}$. WCE can be also applied in the surveillance of polyposis of the small bowel ${ }^{40)}$.

Thomson et al. ${ }^{41)}$ reported the clinical application of WCE in 28 pediatric patients with suspected small bowel disease. They found WCE to be more sensitive than radiographic or endoscopic investigations, and led to management alteration in $64 \%$ of the patients evaluated. In a prospective study by Sharmir et al. ${ }^{42)}$ in 10 children with functional abdominal pain, significant abnormalities were diagnosed in 4 children whose radiologic and laboratory results showed no specific abnormality.

The capsule is either swallowed or placed endoscopically, and the patient can then resume daily activities. The recording device is removed after 8 hours, and the recorded pictures are downloaded. The capsule moves down with bowel movement and is usually passed out within 24 hours.

Patients older than 10 years can often swallow the capsule with only water. Endoscopic placement of capsule has been reported in patients as young as 2.5 years old, weighing $12 \mathrm{~kg}^{43,44)}$.

The main complication of WCE is retention in the bowel; that is, the capsule does not pass out for a minimum of 2 weeks. This event occurs in patients with obscure GI bleeding (1.5\%), Crohn's disease (5\%), and previous small bowel obstruction or surgery. When compared with barium studies, WCE was considered diagnostic in $45 \%$ of patients versus $27 \%$, with $31 \%$ versus $5 \%$ of the causes of obscure bleeding being found ${ }^{45}$.

The current contraindications of capsule endoscopy are pregnancy; GI stricture or fistula; and implanted cardiac pacemaker, defibrillator, or any medical devices in the body.

\section{Narrow band imaging}

This procedure is a high-resolution endoscopic imaging technology that utilizes optical filters and light wavelengths of narrow bands to enhance the microvasculature of mucosal surfaces. The white light goes through a XENON lamp and is dispersed into a narrow band blue light that is absorbed by hemoglobin and displays the superficial capillary network, while the green light penetrates the deeper tissue. This technology is used simultaneously with endoscopy, with no limitation of the visual field and no requirement for a dye. It is helpful to detect early changes in the microvasculature and mucosal abnormalities in dysplastic lesions, such as high-grade dysplasia in patients with ulcerative colitis (UC), and in early detection of Barrett's esophagus ${ }^{46)}$.

\section{Chromoendoscopy}

This is an endoscopic technique that uses dyes to enhance visualization of abnormal-appearing mucosa during endoscopy. No special equipment is required. The dye and a spray catheter are used. The dyes or stains are Lugol's solution, toludine blue, methylene blue, crystal violet, indigo carmine, Congo red, and phenol red. This endoscopic method is useful in pediatric patients for detection of villous atrophy in celiac disease ${ }^{47}$, early detection of high-grade 
dysplasia in UC surveillance ${ }^{48)}$, detection of Barrett's esophagus ${ }^{49)}$, and differentiation of adenomatous polyps from hyperplastic polyps.

\section{Conclusion}

Most hospitals in this country do not have enough staff in the endoscopy unit; thus, it is not possible to keep all the reported guidelines in the endoscopic manuals from developed countries. However, by understanding and familiarizing ourselves with the important rules and methods for GIE, the procedure can be performed efficiently and safely, and furthermore pediatric patients can be examined comfortably.

\section{References}

1) Rudolph CD, Winter HS. NASPGN guidelines for training in pediatric gastroenterology. NASPGN Executive Council NASPGN Training and Education Committee. J Pediatr Gastroenterol Nutr 1999;29 Suppl 1:S126.

2) Messeri A, Caprilli S, Busoni P. Anaesthesia induction in children: a psychological evaluation of the efficiency of parent's presence. Paediatr Anaesth 2004;14:551-6.

3) Brewer S, Gleditsch SL, Syblik D, Tietjens ME, Vacik HW. Pediatric anxiety: child life intervention in day surgery. J Pediatr Nurs 2006;21:1322.

4) Mahajan L, Willie R, Steffen R, Kay M, Kitaoka G, Dettorre J, et al. The effects of a psychological preparation program on anxiety in children and adolescents undergoing gastrointestinal endoscopy. J Pediatr Gastroenterol Nutr 1998;27:161-5.

5) Fox VL. Gastrointestinal endoscopy. In: Walker WA, Goulet O, Kleinman RE, Sherman PM, Shneider BL, Sanderson IR, editors, Pediatric gastrointestinal disease. 4th ed. Hamilton: BC Decker Inc, 2004:1685

6) Cote CJ, Goudsouzian NG, Liu LM, Dendrick DF, Szyfeiben SK. Assessment of risk factors related to the acid aspiration syndrome in pediatric patients: gastric $\mathrm{pH}$ and residual volume. Anesthesiology 1982; 56:70-2.

7) Benaroch LM, Rudolph CD. Introduction to pediatric esophagogastroduodenoscopy and enteroscopy. Gastrointest Endosc Clin N Am 1994; 4:121-42.

8) Ingebo KR, Rayhorn NJ, Hecht RM, Shelton MT, Silber GH, Shub MD. Sedation in children: adequacy of two-hour fasting. J Pediatr 1997;131:155-8.

9) Schreiner MS, Triebwasser A, Keon TP. Ingestion of liquids compared with preoperative fasting in pediatric outpatients. Anesthesiology 1990; 72:593-7.

10) ASGE Standards of Practice Committee, Lee KK, Anderson MA, Baron TH, Banerjee S, Cash BD, Dominitz JA, et al. Modifications in endoscopic practice for pediatric patients. Gastrointest Endosc 2008;67:19

11) Korean Society of Gastrointestinal Endoscopy. Statement about pediatric gastrointestinal endoscopy. Available from : URL://http://www.gie.or.kr
12) Bishop P, Nowicki M, May W, Elkin D, Parker PH. Unsedated upper endoscopy in children. Gastrointest Endosc 2002;55:624-30.

13) Gilger MA. Conscious sedation for endoscopy in the pediatric patient. Gastroenterol Nurs 1993;16:75-9.

14) Balsells F, Wyllie R, Kay M, Steffen R. Use of conscious sedation for lower and upper gastrointestinal endoscopic examinations in children, adolescents and young adults: a twelve year review. Gastrointest Endosc 1997; 45:375-80.

15) Smith C, Rowe RD, Vlad P. Sedation of children for cardiac catheterization with ataractic mixture. Can Anaesth Soc J 1958;5:35-43.

16) Powers KS, Nazarian EB, Tapyrik SA, Kohli SM, Yin H, van der Jagt $\mathrm{EW}$, et al. Bispectral index as a guide for titration of propofol during procedural sedation among children. Pediatrics 2005;115:1666-74.

17) Hussein SA. Anesthesia for pediatric endoscopies. Int Anesthesiol Clin 2006;44:81-93.

18) Law AK, Ng DK, Chan KK. Use of intramuscular ketamine for endoscopy sedation in children. Pediatr Int 2003;45:180-5.

19) Mamula P, Markowitz JE, Neiswender K, Zimmerman A, Wood S, Garofolo M, et al. Safety of intravenous midazolam and fentanyl for pediatric GI endoscopy: prospective study of 1578 endoscopies. Gastrointest Endosc 2007;65:203-10.

20) Barbi E, Petaros P, Badina L, Pahor T, Giuseppin I, Biasotto E, et al. Deep sedation with propofol for upper gastrointestinal endoscopy in children, administered by specially trained pediatricians: a prospective case series with emphasis on side effects. Endoscopy 2006; 38:368-75.

21) Xiao D, Wang F, Wang X, Tang W, Ouyang W, Shen S. Propofol combined with midazolam intravenous sedation anesthesia in pediatric upper gastrointestinal endoscopy. Zhong Nan Da Xue Xue Bao Yi Xue Ban 2009;34:595-8.

22) Tolia V, Peters JM, Gilger MA. Sedation for pediatric endoscopic procedures. J Pediatr Gastroenterol Nutr 2000;30:477-85.

23) Rothbaum RJ. Complications of pediatric endoscopy. Gastrointest Endosc Clin N Am 1996;6:445-9.

24) Guidelines for the elective use of conscious sedation, deep sedation, and general anesthesia in pediatric patients. Committee on Drugs. Sections on anesthesiology. Pediatrics 1985;76:317-21.

25) Antibiotic prophylaxis for gastrointestinal endoscopy. American Society for Gastrointestinal Endoscopy. Gastrointest Endosc 1995;42:630-5.

26) Gersony WM, Hayes CJ. Bacterial endocarditis in patients with pulmonary stenosis, aortic stenosis, or ventricular septal defect. Circulation 1977;56 (1 Suppl):I84-7.

27) Durack DT. Prevention of infective endocarditis. N Engl J Med 1995;332:38-44.

28) Schlaeffer F, Riesenberg K, Mikolich D, Sikuler E, Niv Y. Serious bacterial infections after endoscopic procedures. Arch Intern Med 1996;156:572-4.

29) Gottrand F, Michaud L. Percutaneous endoscopic gastrostomy and gastro-esophageal reflux: are we correctly addressing the question? J Pediatr Gastroenterol Nutr 2002;35:22-4.

30) Rey JR, Axon A, Budzynska A, Kruse A, Nowak A. Guidelines of the European Society of Gastrointestinal Endoscopy (E.S.G.E.) antibiotic prophylaxis for gastrointestinal endoscopy. European Society of Gastrointestinal Endoscopy. Endoscopy 1998;30:318-24.

31) Snyder J, Bratton B. Antimicrobial prophylaxis for gastrointestinal procedures: current practices in North American academic pediatric programs. J Pediatr Gastroenterol Nutr 2002;35:564-9. 
32) Allison MC, Sandoe JAT, Tighe R, Simpson IA, Hall RJ, Elliott TSJ. Antibiotic prophylaxis in gastrointestinal endoscopy prepared on behalf of the Endoscopy Committee of the British Society of Gastroenterology. Gut 2009;58:869-80.

33) Rothbaum RJ. Complications of pediatric endoscopy. Gastrointest Endosc Clin N Am 1996;6:445-59.

34) Bendig DW. Pulse oximetry and upper intestinal endoscopy in infants and children. J Pediatr Gastroenterol Nutr 1991;12:39-43.

35) Fleischer DE, al-Kawas F, Benjamin S, Lewis JH, Kidwell J. Prospective evaluation of complications in an endoscopy unit: use of the A/S/G/E quality care guidelines. Gastrointest Endosc 1992;38:411-4.

36) Guzman C, Bousvaros A, Buonomo C, Nurko S. Intraduodenal hematoma complicating intestinal biopsy: case reports and review of the literature. Am J Gastroenterol 1998;93:2547-50.

37) Spach DH, Silverstein FE, Stamm WE. Transmission of infection by gastrointestinal endoscopy and bronchoscopy. Ann Intern Med 1993;118:117-28.

38) Preud'Homme DL, Michail S, Hodges C, Milliken T, Mezoff AG. Use of wireless capsule endoscopy in the management of severe Henoch Shoenlein purpura. Pediatrics 2006;118:e904-6.

39) Silbermintz A, Sahdev I, Moy L, Vlachos A, Lipton J, Levine J. Capsule endoscopy as a diagnostic tool in the evaluation of graft-vs.-host disease. Pediatr Transplant 2006;10:252-4.

40) Caspari R, von Faulkenhausen M, Krautmacher C, Schild H, Heller J, Sauerbruch T. Comparison of the capsule endoscopy and magnetic resonanance imaging for the detection of polyps of the small intestine in patients with familiar adenomatous polyposis or with Peutz-Jergher syndrome. Endoscopy 2004;36:1054-9.

41) Thomson M, Fritscher-Ravens A, Mylonaki M, Swain P, Eltumi M, Heuschkel R, et al. Wireless capsule endoscopy in children: a study to assess diagnostic yield in small bowel disease in paediatric patients. J Pediatr Gastroenterol Nutr 2007;44:192-7.

42) Shamir R, Hino B, Hartman C, Berkowits D, Eshach-Adiv O, Eliakim $\mathrm{R}$. Wireless video capsule endoscopy in pediatric patients with functional adbominal pain. J Pediatr Gastroenterol Nutr 2007;44:45-50.

43) Kavin H, Berman J, Martin T, Feldman A, Forsey-Koukol K. Successful wireless capsule endoscopy for a 2.5 year old child: obscure gastrointestinal bleeding from mixed juvenile capillary hemangioma-angiomatosis of the jejunum. Pediatrics 2006;117:539-43.

44) Cave D, Legnani P, de Franchis R, Lewis BS; ICCE. ICCE consensus for capsule retention. Endoscopy 2005;37:1065-7.

45) Costamagna G, Shah SK, Riccioni ME, Foschia F, Mutignani M, Perri $\mathrm{V}$, et al. A prospective trial comparing small bowel radiographs and video capsuleendoscopy for suspected small bowel disease. Gastroenterology 2002;123:999-1005.

46) Yoshida T, Inoue H, Usui S, Satodate H, Fukami N, Kudo SE. Narrow band imaging with magnifying endoscopy for superficial esophageal lesions. Gastrointest Endosc 2004;59:288-95.

47) Siegel LM, Stevens PD, Lightdale CJ, Green PH, Goodman S, Garcia-Carrasquillo RJ, et al. Combined magnification endoscopy with chromoendoscopy in the evaluation of patients with suspected malabsorption. Gastrointest Endosc 1997;46:226-30.

48) Matsumoto T, Nakamura S, Jo Y, Yao T, Iida M. Chromoscopy might improve diagnostic accuracy in cancer surveillance for ulcerative colitis. Am J Gastroenterol 2003;98:1827-33.

49) Amano Y, Kushiyama Y, Ishihara S, Yuki T, Miyaoka Y, Yoshino N, et al. Crystal violet chromoendoscopy with mucosal pit pattern diagnosis is useful for surveillance of short segment Barrett's esophagus. Am J Gastroenterol 2005;100:21-6. 